\title{
Migration of myogenic cells in the rat extensor digitorum longus muscle studied with a split autograft model
}

\author{
Gregg D. Phillips ${ }^{1}$, John R. Hoffman ${ }^{2}$, and David R. Knighton ${ }^{1}$ \\ ${ }^{1}$ Department of Surgery, University of Minnesota, Minneapolis, Minnesota, USA and ${ }^{2}$ Department of Biological Sciences, University \\ of Michigan, Ann Arbor, Michigan, USA \\ Accepted April 10, 1990
}

\begin{abstract}
Summary. The ability of myogenic cells to migrate perpendicular to the long axis of freely autografted muscles was examined. Rat extensor digitorum longus muscles were divided, and one half was devitalized by repeated freezing in liquid nitrogen while the other half was kept viable in physiologic saline. The halves were reunited with sutures and grafted back into the original muscle bed. At intervals between 5 and 25 days the grafts were removed and examined histologically for the presence of myotubes within the devitalized region. Myotubes were first seen in the devitalized half 10 days postgrafting with the maximum number of myotubes observed after 12 to 15 days. These results indicate that myogenic cells are capable of migration perpendicular to the long axis of the muscle fibers in an autograft.
\end{abstract}

Key words: Skeletal muscle - Myogenic cells - Regeneration - Motility - Grafts - Rat (F-455 strain)

Three distinct zones are established in a freely autografted muscle as it regenerates: a peripheral zone of surviving muscle fibers, a middle zone of regenerating muscle, and a central zone of necrotic muscle fibers. With time, the middle zone increases in size at the expense of the central zone until the graft is filled with regenerated muscle (Carlson et al. 1979). The myogenic cells in the central zones of freely grafted muscles die after $4 \mathrm{~h}$ in an ischemic environment (Phillips et al. 1987). Although the central zones persist in excess of $4 \mathrm{~h}$ (for days or even weeks), the grafts are eventually filled with regenerated muscle. Therefore, the precursor cells for the new fibers must originate outside of the central ischemic core and migrate in.

Send offprint requests to: Dr. Gregg D. Phillips, University of Minnesota, Box 120 UMHC, Department of Surgery, Minneapolis, Minnesota 55455, USA
The peripheral zone of surviving muscle fibers could serve as the origin of these precursor cells, if myogenic cells are capable of migrating perpendicular to the muscle's long axis. Migration of myogenic cells has been studied by several investigators. Electron-microscopic observations of rat tibialis anterior and mouse lumbrical muscles led Schultz (1978) to conclude that myogenic cells migrate out of the basal lamina into the interstitial space in response to denervation. The studies of Jones (1979) and Lipton and Schultz (1979), based on electronmicroscopic and autoradiographic examination, demonstrated that $95 \%$ of labeled myogenic cells injected into rat and Japanese quail muscles migrated away from the site of injection and eventually fused to pre-existing myofibers, whereas $5 \%$ fused with one another to form myotubes in the interstitium. Bischoff (1979) noted that in vitro, myogenic cells migrated away from single muscle fibers through tears in the basal laminae. In more recent experiments, Schultz et al. $(1985,1986)$ froze or crushed one portion of the rat extensor digitorum longus muscle and monitored regeneration and mitotic activity of myogenic cells in both the damaged and undamaged regions using histologic and autoradiographic methods. Their results demonstrated the ability of myogenic cells to migrate parallel to the long axis of a muscle from uninjured areas to injured regions. Furthermore, Schultz et al. (1986) showed the ability of myogenic cells to migrate transversely from adjacent muscles when the epimysiums of the opposed muscles were disrupted.

A split autograft model was employed in the present study to determine if intrinsic myogenic cells possess the capacity to migrate perpendicular to the long axis of a muscle graft toward the ischemic central core. The rat extensor digitorum longus (EDL) muscle was split longitudinally. One half was devitalized and the other half kept viable. The two halves were sutured together and grafted back into the rat. Subsequent presence of myotubes in the devitalized half of the graft would suggest that myogenic cells are indeed capable of migration perpendicular to the long axis of a muscle. 


\section{Materials and methods}

Devitalized/viable grafts. Adult rats $(250-300 \mathrm{gm})$ were obtained from the F-455 strain maintained at the University of Michigan. Rats were anesthetized with ether. An incision was made along the lateral aspect of one rat hindlimb from the knee to the ankle. The subcutaneous fascia was split, and the EDL muscle was removed from its bed by severing its tendons of origin and insertion, and the neurovascular supply. The muscle was then sectioned longitudinally with a cut paralleling the muscle fibers to minimize the number of damaged fibers. One half of the muscle was placed in $0.9 \% \mathrm{NaCl}$. The other half was devitalized by freezing it in liquid nitrogen for $30 \mathrm{sec}$ followed by thawing in $0.9 \% \mathrm{NaCl}$ (Ghins et al. 1984, 1985; Schultz et al. 1986). The freeze and thaw procedure was repeated 3 times. The tendon-stumps in the animal were devitalized by pinching them with forceps cooled in liquid nitrogen. The two halves of the muscle were rejoined with silk sutures and grafted into the original EDL muscle-bed. No attempts were made to anastomose the transected artery or to rejoin the nerve. The overlying fascia and the skin were closed with sutures. The grafting periods were 5-9 $(n=8), 10-15(n=25)$, and 16-25 $(n=8)$ days, after which times the EDL muscles were fixed in Bouin's solution and embedded in paraffin. For histological examination, $7 \mu \mathrm{m}$ thick, serial longitudinal sections and mid-graft cross-sections were cut and stained with hematoxylin and eosin. The presence of myotubes within the devitalized region was considered as evidence for the migration of myogenic cells.

Control grafts. The controls grafts were of 3 varieties: 1) a nonfrozen, freely autografted EDL muscle $(n=12) ; 2)$ a devitalized freely autografted EDL muscle ( $n=24)$; and 3 ) an autograft in which the EDL muscle was split and both pieces were frozen and sutured together (devitalized/devitalized) $(n=8)$.

Postoperatively, all rats were provided with tetracycline water $(15 \mathrm{mg} / \mathrm{ml})$ and rat chow ad libitum.
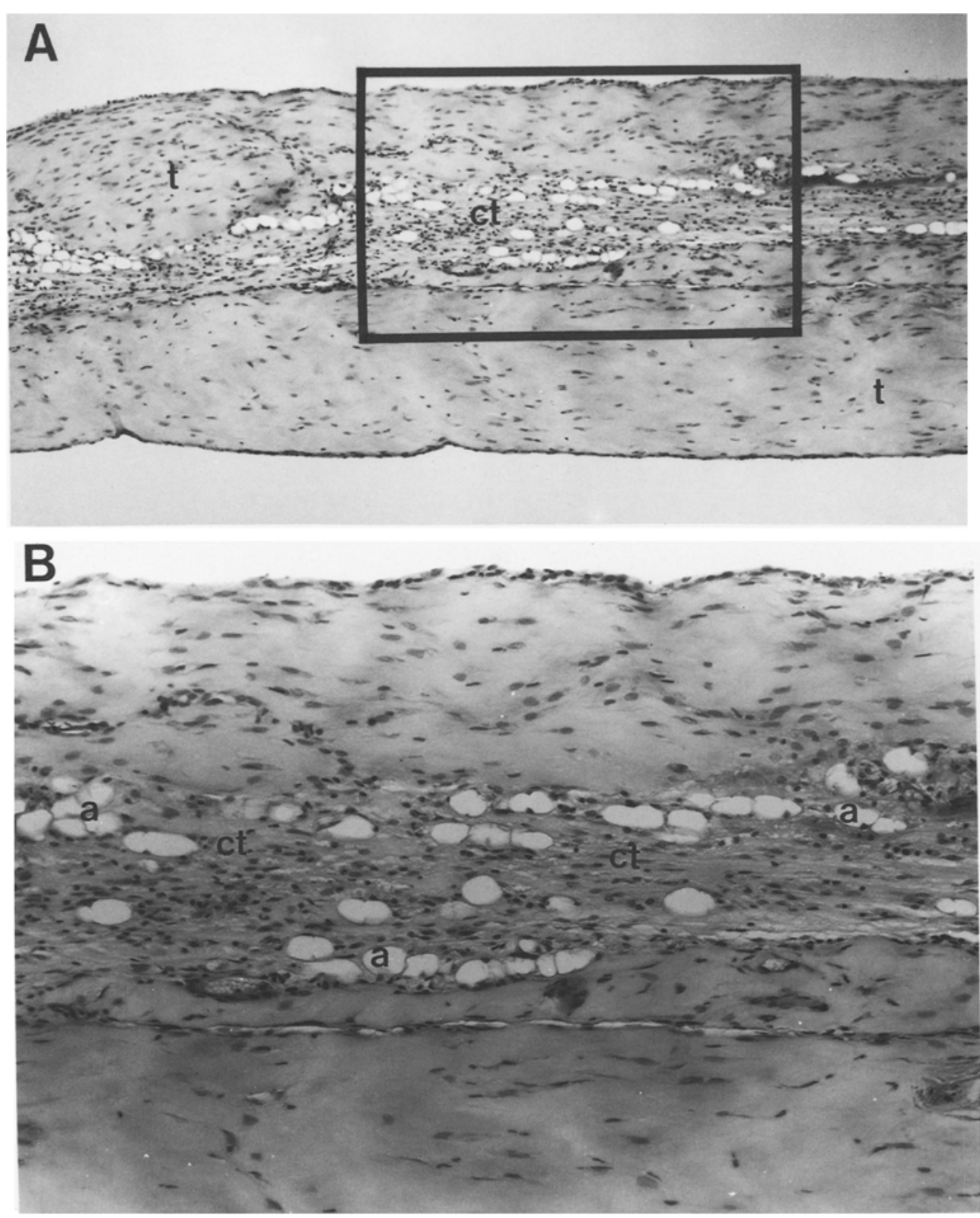

Fig. 1A, B. 20-day devitalized EDL muscle graft. A Low magnification photograph demonstrating that majority of graft is composed of tendon $(t)$, and connective tissue $(c t)$. $\mathrm{H} \& \mathrm{E}$ $\times 70$. B High magnification photograph of boxed region in 1 A showing loose connective tissue (ct), adipose tissue (a), and absence of muscle regeneration. $\mathrm{H} \& \mathrm{E} \times 140$ 


\section{Results}

Control grafts. The freely autografted EDL muscles regenerated typically (Carlson et al. 1979). After grafting, all but the most peripheral fibers underwent ischemic necrosis. Two or 3 days postgrafting, small capillaries had reached the surface of the graft, penetrated the periphery of the graft by days 4 and 5 , and began revascularization of the ischemic central core. These vessels were accompanied by macrophages and the formation of myotubes. The capillaries and the regenerative process proceeded centripetally, so that by 7 to 10 days after grafting all of the necrotic muscle had been replaced by regenerating fibers with central nuclei. Between 10 and 25 days postgrafting, many of the central nuclei had migrated to the periphery of the maturing muscle fibers. The devitalized EDL muscles showed no sign of muscle regeneration, with the exception of an occasional myotube near the proximal end of the graft. The early grafts were composed of necrotic muscle fibers, which were replaced by granulation tissue and adipose tissue with increasing age of the graft (Fig. 1). The devitalized/devi-
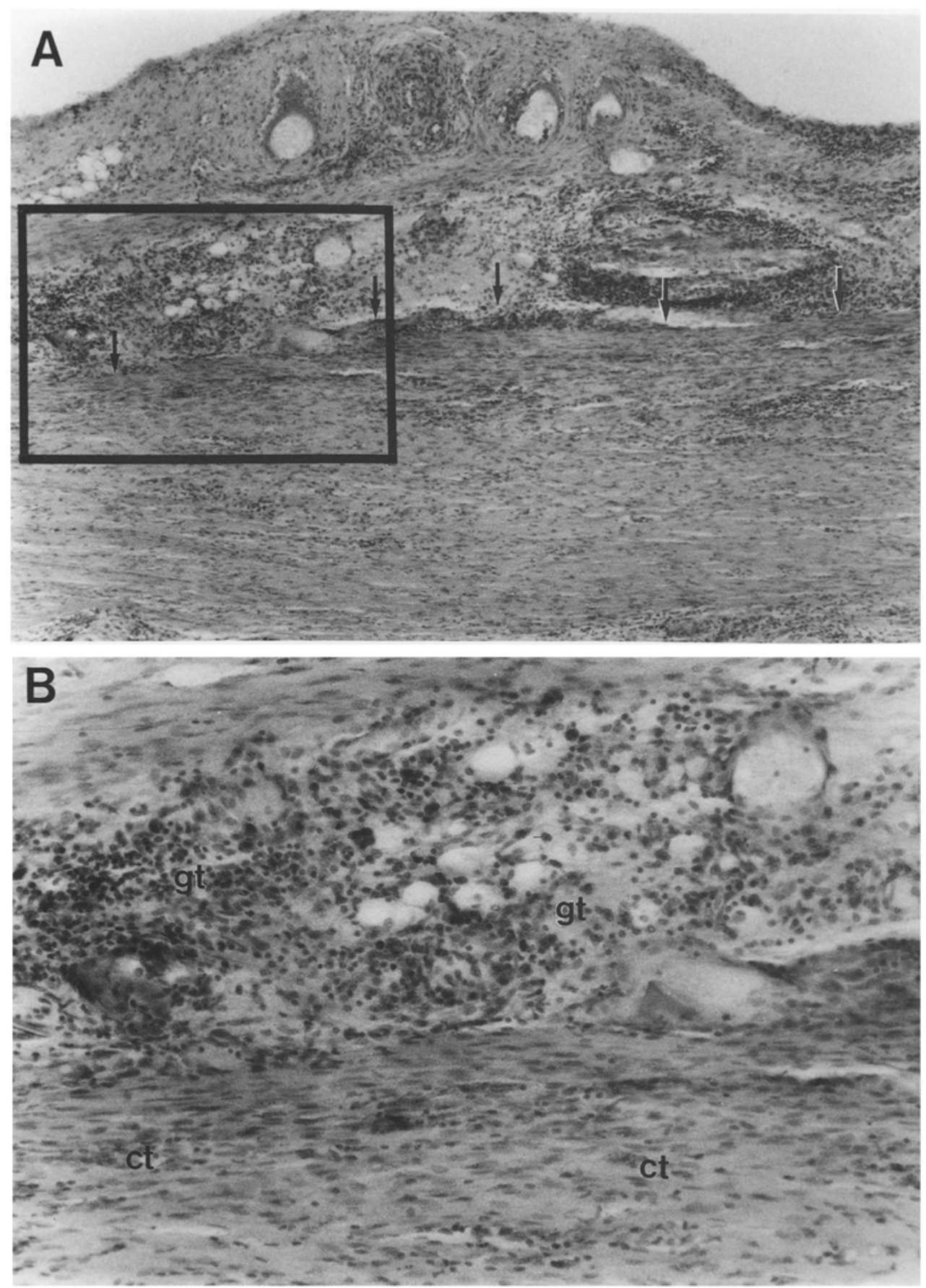

Fig. 2A, B. 15-day devitalized/ devitalized EDL muscle graft. A Low-magnification photograph showing border between 2 devitalized halves of graft (arrows). H \& E $\times 60$. B Highmagnification photograph of boxed region in $\mathbf{A}$. Graft is composed of granulation tissue $(g t)$ and connective tissue $(c t)$. No myotubes are present. $\mathrm{H} \& \mathrm{E}$ $\times 170$ 

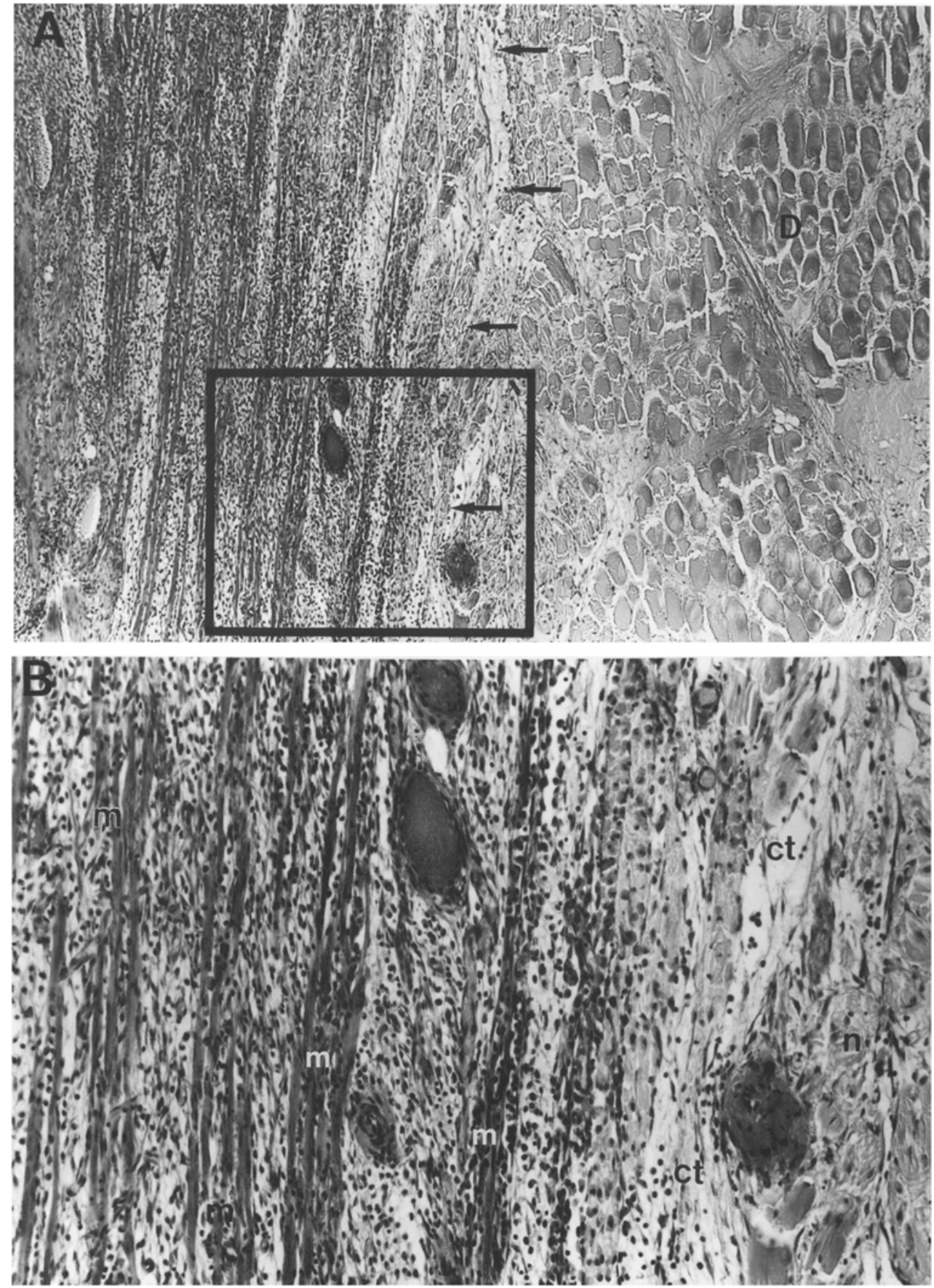

Fig. 3A, B. 7-day devitalized/ viable EDL muscle graft. A Low magnification photograph demonstrating that muscle regeneration has progressed to interface (arrows) between viable $(V)$ and devitalized $(D)$ portions of graft. $\mathrm{H} \& \mathrm{E} \times 50$. B Highmagnification photograph of boxed region in A. Myotubes $(m)$ occupy viable half, whereas devitalized half contains loose connective tissue $(c t)$ and necrotic muscle fibers $(n)$. When 2 halves of muscle are sutured together and returned to muscle bed, they are not necessarily under the same amount of tension. Because architecture of regenerating muscle is dependent on tension, divergent fiber orientation can occur. Result is presence of obliquely sectioned fibers in devitalized region and longitudinally sectioned myotubes in viable portion, as seen in this figure. $\mathrm{H} \& \mathrm{E}, \times 150$ talized grafts were composed primarily of tendon, adipose tissue, and collagen. Isolated myotubes were rarely observed in these grafts (Fig. 2).

5 to 9-day experimental grafts. Gross observation revealed 2 distinct halves in each of the early grafts. The frozen halves were pale and appeared avascular. In contrast, the viable halves were red-yellow and exhibited numerous small blood vessels on their surfaces. The frozen sides were shorter than the viable portions due to shrinkage during devitalization. Serial longitudinal sections demonstrated more dramatic differences between the halves of the muscle. The frozen regions contained necrotic muscle and a few invading macrophages, which appeared in greater numbers as the grafting periods increased. In contrast, the viable sides exhibited typical muscle regeneration with numerous macrophages, sinuslike blood vessels, and myotubes occupying the periphery (Carlson et al. 1979). As the age of the grafts increased, this regenerative process progressed, reaching the interface of the devitalized and viable regions between 7 and 9 days postgrafting (Fig. 3). Cross-sectional analysis confirmed these observations, and in addition, revealed that muscle regeneration progressed more rap- 

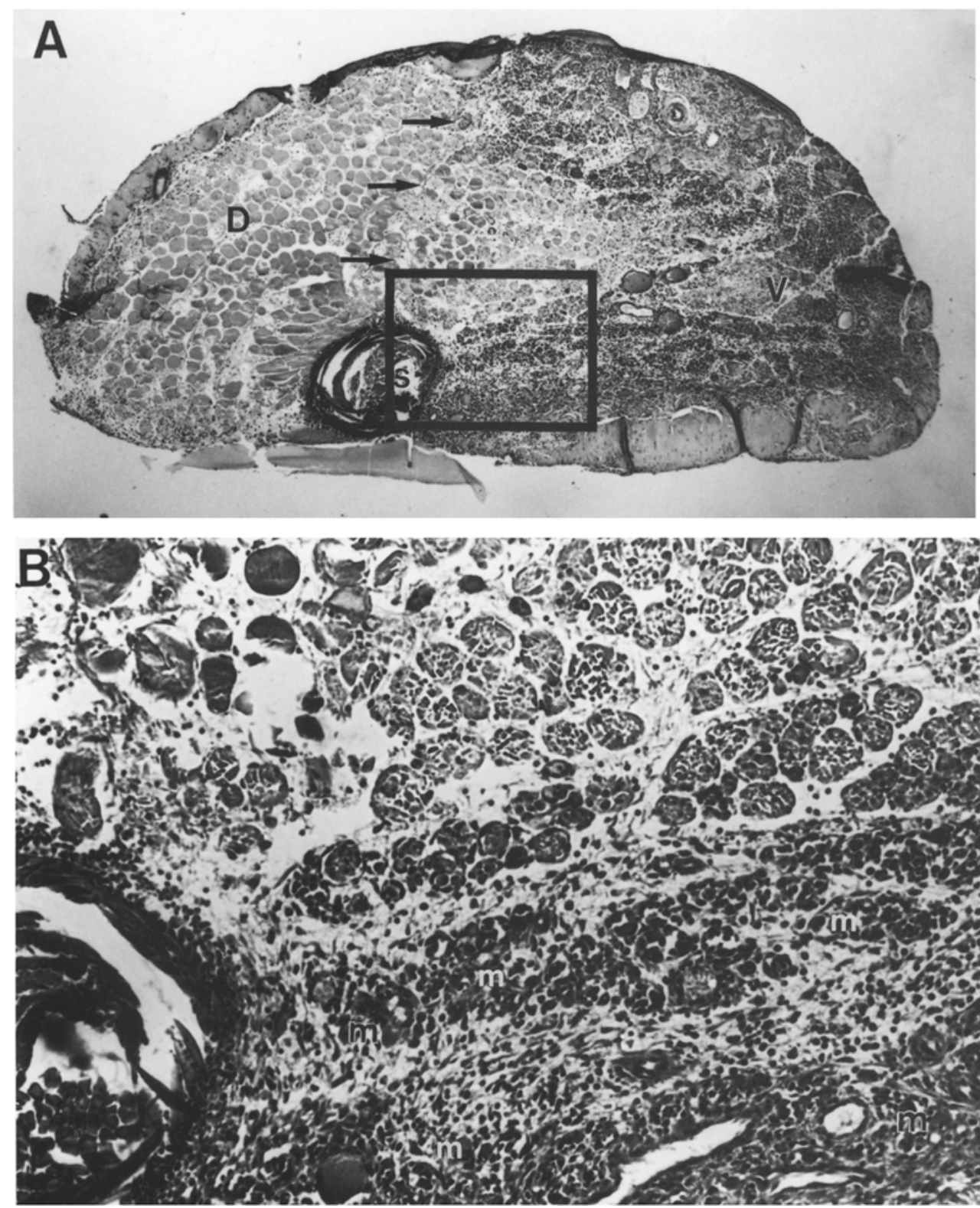

Fig. 4A, B. Cross-section of 7-day devitalized/viable EDL muscle graft made at mid-belly. A Regenerative process has reached interface (arrows) between devitalized $(D)$ and viable $(V)$ portions at periphery of graft. One suture $(s)$ is visible in this section. $\mathrm{H} \& \mathrm{E} \times 30$. B Highmagnification photograph of boxed region in A showing crosssectioned myotubes $(m)$ in regenerating part of graft. $\mathrm{H} \& \mathrm{E}$, $\times 100$ idly at the periphery than at the center of the grafts (Fig. 4).

10 to 15-day experimental grafts. Gross distinction between the 2 halves of each graft was difficult without the aid of the sutures. Histological examination showed the first evidence of myogenic cell migration 10 days postgrafting. The viable halves exhibited parallel rows of regenerated muscle fibers with eosinophilic cytoplasm and centrally located nuclei. The devitalized halves contained degenerating muscle fibers, macrophages, fibroblasts, and a small number of myotubes apparently spilling over from the viable portion (Fig. 5). Maximum migration of myogenic cells was seen 12 to 15 days after grafting. All of these grafts exhibited myotubes in the devitalized half, and in $69 \%$, myotubes were observed as far away from the viable region as the periphery of the frozen portion of the graft. In addition, the number of myotubes within the devitalized region increased dramatically over that seen in 10-day grafts (Fig. 6).

16 to 25-day experimental grafts. Unexpectedly, the regenerative process in the older grafts did not appear to progress any further in the devitalized regions. In fact, degenerating myotubes were replaced with loose connective tissue and adipose tissue, a series of changes characteristic of regenerating muscle that fails to become reinnervated (Carlson 1981).

\section{Discussion}

A split autograft model was used to determine if myogenic cells are able to migrate perpendicular to the long 

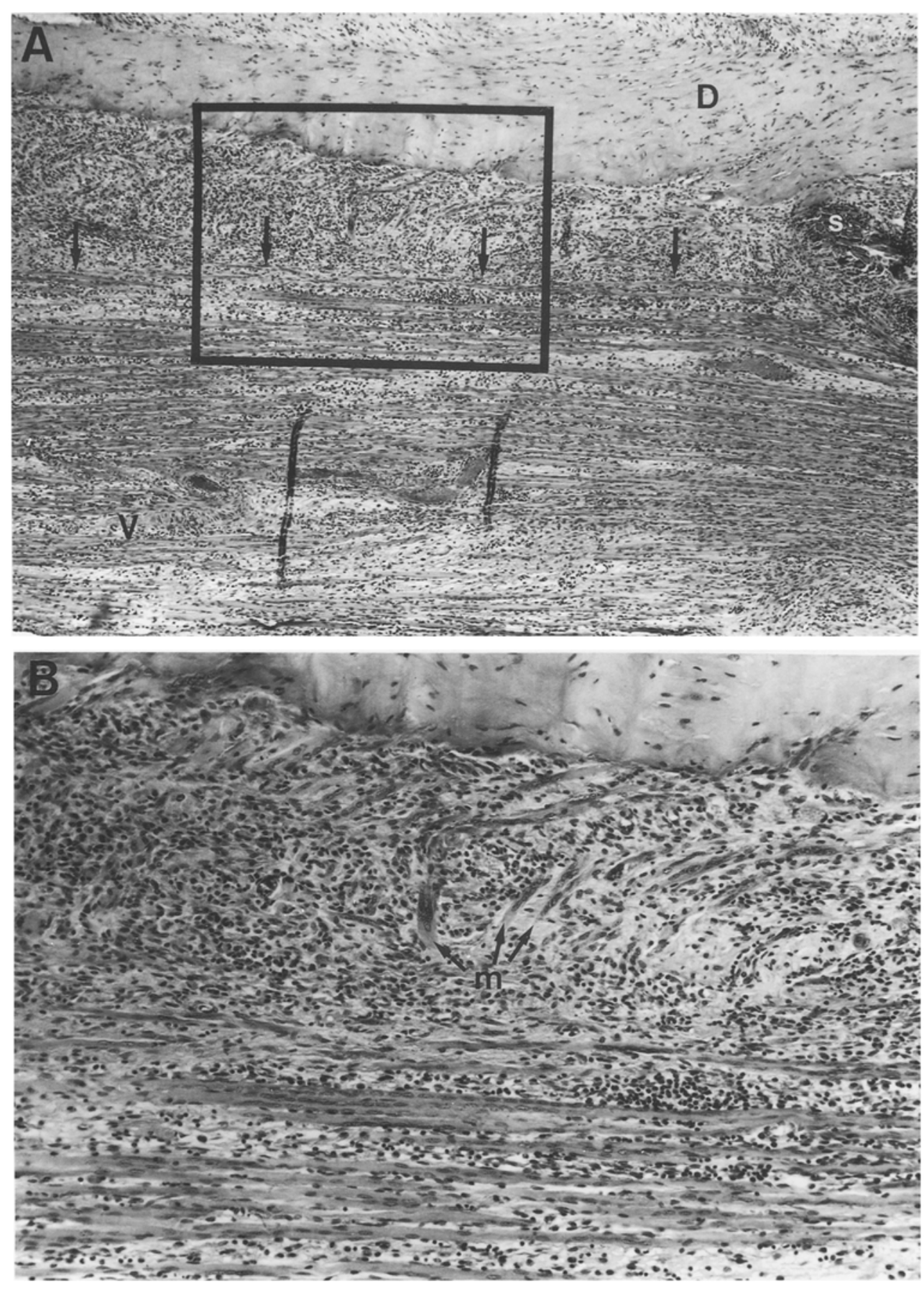

Fig. 5A, B. 10-day devitalized/ viable EDL muscle graft. A Lowmagnification photograph showing junction (arrows) between devitalized $(D)$ and viable $(V)$ portions of graft and a suture $(s)$. H \& E $\times 50$. B Highmagnification photograph of boxed region in $\mathbf{A}$ showing a few myotubes $(m)$ spilling over from the viable half of the graft into the devitalized balf. $\mathrm{H} \& \mathrm{E}$, $\times 100$ axis of a freely autografted muscle. Myotubes in the devitalized half indicated migration of myogenic cells from the viable half. By $12-15$ days after grafting, myotubes were observed as far as the periphery of the devitalized half of the muscle. In addition, the number of myotubes in the devitalized region reached its peak. Therefore, we conclude that myogenic cells do indeed have the capacity to migrate perpendicular to the long axis of a muscle graft.

The control grafts were executed to show that freezing in liquid nitrogen followed by thawing eliminated all viable cells from the graft and to be certain that the viable portion of the split autograft was the only major source of myogenic cells. The intact devitalized rat EDL muscles failed to exhibit any sign of regeneration. The split devitalized grafts were also devoid of myotubes, suggesting that the freeze and thaw technique killed the intrinsic myogenic cells and that the contribution of myogenic cells from exogenous sources, such as macrophages (Yarom et al. 1976), the thymus (Wekerle et al. 1975), the pineal gland (Freschi et al. 1979), glia (Lennon and Peterson-1979), fibroblasts (Constantinides et al. 1977), pericytes (Freund-Molbert and Ketelsen 1973), adjacent muscle via the circulation (Bateson et al. 1967), or other means was negligible. These results confirm the data reported by Ghins et al. $(1984,1985)$, and 

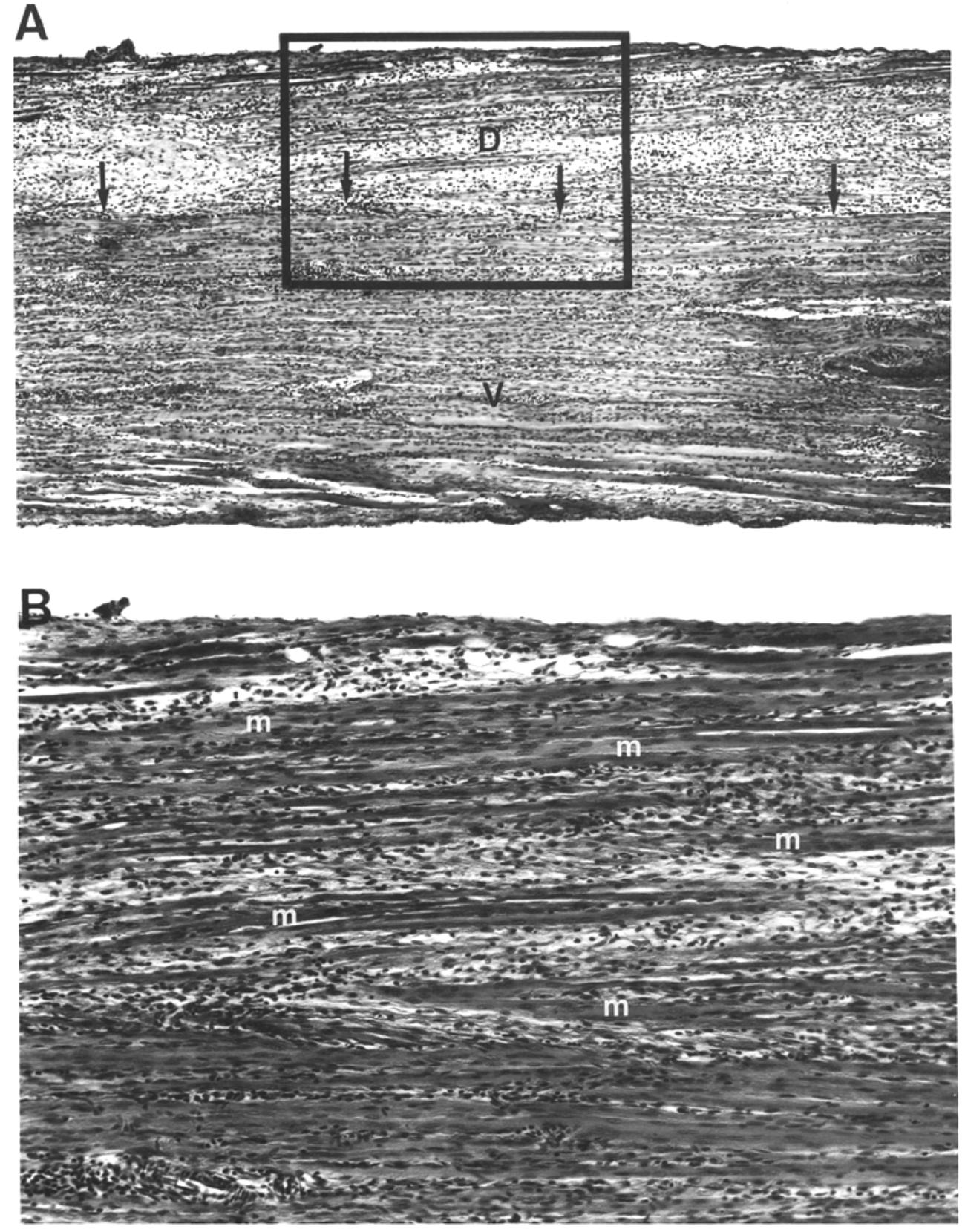

Fig. 6A, B. 13-day devitalized/ viable EDL muscle graft. A Lowmagnification photograph showing interface (arrows) between devitalized $(D)$ and viable ( $V$ ) halves of graft. $\mathrm{H} \& \mathrm{E}$, $\times 50$. B High-magnification photograph of boxed area in $\mathbf{A}$ exhibiting large number of myotubes $(m)$ as far as periphery of devitalized portion of graft. $\mathrm{H} \& \mathrm{E}, \times 130$
Schultz et al. (1986). On the other hand, our results are in conflict with a number of other investigators. Partridge et al. (1978), Grounds et al. (1980), Grounds and Partridge (1983), Watt et al. (1987), and Morgan et al. (1987) allografted either intact or minced muscles between strains of mice with different genetic variants of glucose-6-phosphate isomerase (GPI). Electrophoretic analysis detected donor and host isomerases, and occasionally host-donor hybrid isomerase in the grafts. The influx of any host cells could be responsible for the presence of host GPI, but host-donor hybrid GPI could only result from the fusion of host and donor myogenic cells. Therefore, the authors concluded that myogenic cells from an exogenous source, namely adjacent muscles, contributed to the regeneration of these grafts.

Although different laboratory techniques could be responsible for the divergent data from these 2 groups, a more likely explanation is the difference in experimental animals used. In our laboratory and those of Ghins and Schultz rats were used, whereas Partridge, Grounds, Watt, and Morgan used mice. The epimysium of rat muscle is thicker than that of mice and may act as an effective barrier to myogenic cell migration. In fact, Schultz et al. (1986) showed that myogenic cells from rat muscle could migrate to an adjacent devitalized muscle only if the epimysium of both muscles was disrupted. The greater absolute distances that myogenic cells would have to migrate in the rat versus the mouse would also be prohibitive.

Our results and the data of Phillips et al. (1987) lend support to the hypothesis that myogenic cells survive in the periphery of a muscle graft and migrate perpendic- 
ular to the muscle's long axis to give rise to regenerating muscle in the ischemic central core of the graft. The stimulus for this migration is speculative at this point. Venkatasubramanian and Solursh (1984) demonstrated that chick embryonic myoblasts migrate toward a gradient of platelet-derived growth factor (PDGF) and PDGF-like factors in a modified Boyden chamber assay, and suggested that the vasculature is the source of these factors. Bischoff (1986) prepared an extract from crushed skeletal muscle which showed mitogenic activity for embryonic myoblasts and satellite cells of single muscle fibers in vitro. The same extract injected into the flexor digitorum brevis muscle of 1-week-old rat pups for 4 to 5 days stimulated an increase in the DNA content and the number of myonuclei per muscle fiber. Bischoff speculated that this factor may be chemotactic as well. The findings of Schultz et al. (1985, 1986), demonstrating the migration of myogenic cells, within a muscle and between adjacent muscles, from undamaged areas to regions injured by freeze-thaw, and the results from Maltin et al. (1983) and Klein-Ogus and Harris (1983) showing migration of myogenic cells from nonnecrotic muscle to the site of trauma following the injection of myotoxic snake venom also suggest a chemotactic mechanism.

Using the split autograft model described in this report, we were able to demonstrate that myogenic cells surviving in a viable portion of a muscle graft are capable of migrating perpendicular to the long axis of the muscle into a devitalized region. These results confirm the notion that myogenic cells can migrate great distances to the site of trauma within a muscle, without being constrained by the endomysium or perimysium. Furthermore, we showed that myogenic cells from exogenous sources do not make a significant contribution to the regeneration of devitalized muscle grafts in the rat. Once we understand the migratory capacity of myogenic cells and their source, we can focus our attention on determining the stimulus for the initiation and direction of their movement, with the ultimate goal of controlling their motility to improve the regeneration of skeletal muscle.

Acknowledgements. This work was supported by NIH grant PO1 DE 7687 and a Rackham Fellowship.

\section{References}

Bateson RG, Woodrow DF, Sloper JC (1967) Circulating cell as a source of myoblasts in regenerating injured mammalian skeletal muscle. Nature 213:1035-1036

Bischoff R (1979) Tissue culture studies on the origin of myogenic cells during muscle regeneration in the rat. In: Mauro A et al. (eds) Muscle Regeneration. Raven Press, New York, pp 13-29

Bischoff R (1986) A satellite cell mitogen from crushed adult muscle. Dev Biol 115:140-147
Carlson BM, Hansen-Smith FM, Magon DK (1979) The life history of a free muscle graft. In: Mauro A et al. (eds) Muscle Regeneration. Raven Press, New York, pp 493-507

Carlson BM (1981) Denervation, reinnervation, and regeneration of skeletal muscle. Otolaryngol Head Neck Surg 89:192-196

Constantinides PG, Jones PA, Gevers W (1977) Functional striated muscle cells from non-myoblast precursors following 5-azacytidine treatment. Nature 267:364-366

Freschi JE, Parfitt AG, Shain WG (1979) Electrophysiology and pharmacology of striated muscle fibres cultured from dissociated neonatal rat pineal glands. J Physiol 293:1-10

Freund-Molbert E, Ketelsen U-P (1973) The regeneration of the human striated muscle cell. Beitr Pathol Bd 148:35-54

Ghins E, Colson-Van Schoor M, Marechal G (1984) The origin of muscle stem cells in the triceps surae regenerating after mincing. J Musc Res Cell Mot 5:711-722

Ghins E, Colson-Van Schoor M, Maldague P, Marechal G (1985) Muscle regeneration induced by cells autografted in adult rats. Arch Int Phys Biochim 93:143-153

Grounds M, Partridge TA, Sloper JC (1980) The contribution of exogenous cells to regenerating skeletal muscle: An isoenzyme study of muscle allografts in mice. J Pathol 132:325-341

Grounds M, Partridge TA (1983) Isoenzyme studies of whole muscle grafts and movement of muscle precursor cells. Cell Tissue Res 230:677-688

Jones PH (1979) Implantation of cultured regenerate muscle cells into adult rat muscle. Exp Neurol 66:602-610

Klein-Ogus C, Harris JB (1983) Preliminary observations of satellite cells in undamaged fibers of the rat soleus muscle assaulted by a snake-venom toxin. Cell Tissue Res 230:671-676

Lennon VA, Peterson S (1979) Neurectoderm markers retained in phenotypical skeletal muscle cells arising from a glial cell line. Nature $281: 586-588$

Lipton BH, Schultz E (1979) Developmental fate of skeletal muscle satellite cells. Science 205:1292-1294

Maltin CA, Harris JB, Cullen MJ (1983) Regeneration of mammalian skeletal muscle following the injection of the snake-venom taipoxin. Cell Tissue Res 232:565-577

Morgan JE, Coulton GR, Partridge TA (1987) Muscle precursor cells invade and repopulate freeze-killed muscles. J Musc Res Cell Motil 8:386-396

Partridge TA, Grounds M, Sloper JC (1978) Evidence of fusion between host and donor myoblasts in skeletal muscle grafts. Nature 273:306-308

Phillips GD, Carlson BM, Lu D, Mitashov VI (1987) Survival of myogenic cells in freely grafted rat rectus femoris and extensor digitorum longus muscles. Am J Anat 180:365-372

Schultz E (1978) Changes in satellite cells of growing muscle following denervation. Anat Rec 190:299-312

Schultz E, Jaryszak DL, Valliere CR (1985) Response of satellite cells to focal skeletal muscle injury. Muscle Nerve 8:217-222

Schultz E, Jaryszak DL, Gibson MC, Albright DJ (1986) Absence of exogenous satellite cell contribution to regeneration of frozen skeletal muscle. J Musc Res Cell Mot 7:361-367

Venkatasubramanian K, Solursh M (1984) Chemotactic behavior of myoblasts. Dev Biol 104:428-433

Watt DJ, Morgan JE, Clifford MA, Partridge TA (1987) The movement of muscle precursor cells between adjacent regenerating muscles in the mouse. Anat Embryol 175:527-536

Wekerle H, Paterson B, Ketelson U-P, Feldman M (1975) Striated muscle fibres differentiated in monolayer cultures of adult thymus reticulum. Nature 256:493-494

Yarom R, Behar AJ, Yanko L, Hall TA, Peters PD (1976) Gold tracer studies of muscle regeneration. $J$ Neuropathol Exp Neurol 35:445-457 